\title{
Conceptualising Reuse in African Households: Perspectives from Chembe, Malawi
}

\author{
Marc Kalina $^{1,2}$ (D) Mvuselelo Ngcoya $^{3} \cdot$ Bembeyere Nkhoma $^{4} \cdot$ Elizabeth Tilley $^{1,4}$
}

Received: 7 August 2020 / Accepted: 2 November 2021 / Published online: 14 November 2021

(c) The Author(s) 2021

\begin{abstract}
African households are often models of sustainability, practicing daily behaviours, which, if even not directly associated by the individual with Western conceptualisations of 'recycling' or 'reuse', have dramatically positive impacts on the amounts of household waste generated. However, rarely has the African household been given the same consideration, and there is a poor understanding within the discipline how poor individuals, and Africans in particular, understand and conceptualise 'waste' as both a problem and a resource. Drawing on Kennedy and Appadurai's theoretical perspectives, the purpose of this article is to critically examine and contextualise household solid waste reuse practices in Chembe, Malawi, a rapidly densifying village and a constituent part of one of the nation's premier resort destinations. Drawing on extensive ethnographic fieldwork with residents and stakeholders, findings suggest that, within Chembe, reuse practices, and the motivations that drive them, are both widespread and diverse, with a multitude of 'waste' items living multiple 'lives' before being ultimately discarded as 'trash'. These behaviours are facilitated by the fact that many desirable waste items are widely available locally within Chembe, and although some of these reuse practices may be widespread within Malawi, others have been uniquely fostered by Chembe's position as an affluent tourism destination with abundant and easily accessible waste streams. This investigation is particularly important within the context of rural Africa, and the Global South more broadly. Moreover, it should critically inform circular economy, zero waste, and broader waste management studies discourse, where African households have been habitually treated as problems needing solutions, rather than potential sources of innovation and learning.
\end{abstract}

Keywords Reuse $\cdot$ Solid waste $\cdot$ Africa $\cdot$ Circular economy $\cdot$ Zero waste

Marc Kalina

mkalina@ethz.ch

1 Department of Mechanical and Process Engineering (MAVT), ETH Zurich, Zurich, Switzerland

2 South African Research Chair in Waste and Climate Change, University of KwaZulu-Natal, Durban, South Africa

3 School of Built Environment and Development Studies, University of KwaZulu-Natal, Durban, South Africa

4 Department of Environmental Health, University of Malawi, The Polytechnic, Blantyre, Malawi 


\section{Introduction}

No, I do not know what you mean by 'recycling', but I do often collect broken plastic buckets from shops, in fact you can see a few around my house now. I also own a mop made from old clothes and I frequently make use of [discarded] plastic bottles and old mosquito nets. $^{1}$

Within academia, there is a tendency, as Du Bois (1903) put it, to pathologies Black or African existences and lives; to obsess over Black poverty and focus on all of the individual factors responsible for the condition of the poor, rather than structural conditions that strangle them or discuss the things that they are doing for themselves, to better or improve their own lives. This tendency unfortunately has often manifested within waste management studies, where Africa, and African households in particular, are more frequently viewed as problems that need externally imposed solutions, rather than sources of innovation that can be learned from. Waste discourses and research in the Global South and in Africa in particular, are often framed in terms of failure, that is, a terminal lack of funding or capacity, disconnections over education or social acceptance, or the falling apart of the levers of governance, among other topics of perennial academic critique. In particular, much attention has focused on how non-governmental actors (NGOs, informal waste pickers, etc.) seek to redeem the situation by taking over where states fail. Discussions then predictably range from livelihoods and politics of waste picking (see Alene, 2018; Ali et al., 2019; Almasi et al., 2019; Gandy, 2014; Gutberlet, 2017; Moore, 2012), to decrying the environmental injustice (see (Hird, 2017; Kalina, 2020b; Little \& Lucier, 2017; Weber et al., 2019) and harmful health consequences of waste (see (Kalina et al., 2019; Kang et al., 2013; Okoronkwo et al., 2005). In the former group of studies, the economies of waste collection are viewed as vehicles for livelihood creation. In other words, interacting with 'waste' is the thing of the poor and the marginalised. In most of these studies, the definition of 'waste' is self-evident. Yet we know that what counts as waste is often ambiguous, mutable and depends on social context, time, and space.

Regardless, there remains a paucity of research on solid waste management practices contextualised within Africa, and a lack of detailed studies on individual or household decision-making. Although over the past decade, the 'Discard Studies' movement has significantly advanced how we, as academics, understand how differently placed individuals understand and conceptualise 'waste', African perspectives and voices are still sorely lacking. These omissions are unfortunate. Despite their near-absence from academic discourse, African households are often models of sustainability, practicing daily behaviours, which, if even not directly associated by the individual with Western conceptualisations of 'recycling' or 'reuse', as illustrated in the quote above, have dramatically positive impacts on the amounts of household waste generated, as well as reducing personal and household consumption. When innovative or creative reuse practices have been observed in Western or Asian homes, they have been made the focus of considerable scholarly attention. ${ }^{2}$ However, rarely has the African household been given the same consideration. Why are only the household behaviours or decision-making practices of Western households considered

\footnotetext{
1 Interview \#8, 04/09/2019.

2 See, for instance, the special issue of Worldwide Waste: Journal of Interdisciplinary Studies on 'Reuse and Repair' launched in January 2019, which, although it featured several excellent contributions, was predominantly situated within Western contexts, and lacked African voices completely.
} 
innovative or worthy of investigation? How can we construct a less neo-colonial waste management studies discourse?

The purpose of this article is to begin to bridge this knowledge gap on solid waste reuse practices in African households through an examination of household reuse in Chembe, Malawi, once a small fishing village on Lake Malawi in decades past, but now one of the country's biggest tourist destinations. Drawing on ethnographic and participatory qualitative fieldwork with residents, ${ }^{3}$ we explore the multiplicity of reuse practices that have emerged, both independently of, and in response to, the village's recent prosperity. In particular, we examine the ways in which reuse practices have been able to supplement or sustain livelihoods, as well as interrogating the line by which, for different individuals, a 'waste' object is no longer considered reusable and can ultimately be discarded. Throughout the research process, we have been acutely aware of a lack of theoretical guidance provided within contemporary literature on waste-society relationships. That is not to say that fine critical philosophical, ontological, and epistemological deconstructions of 'waste' are not being written. On the contrary, over the past decade there has been growing interest in the wider role of society and culture in defining and structuring attitudes towards, and behaviours around, waste (see, (Ablitt \& Smith, 2019; Hird, 2012; Reno, 2015; Spelman, 2011; Von Bemmel \& Parizeau, 2019; Viney, 2014)) This includes a more recent increase in perspectives from the Global South (see, for instance Kalina, 2020a; Kalina \& Tilley, 2020; Kalina et al., 2020, a, b; Oloko, 2018; Wang, 2019; Wu \& Zhang, 2019). Furthermore, there has also been growing interest in the connection between tourism and circularity within South settings (see Jarman-Walsh, 2017; Little, 2017; Shaw, 2019; Suradi, 2019; van der Graaf, 2017). However, although these contributions may be valuable, and suggest that waste management studies discourses are embracing more flexible constructions of waste and society, they remain, overwhelmingly focused on the city, on systems, and not the individual, and feel ill-suited for conceptualising behaviour in rural African households. Instead of taking waste as fully knowable, we are motivated by the contributions of anthropologists, philosophers, and sociologists who locate the study of waste, and of wastefulness, in social contexts.

In particular, we draw on the work of Kennedy and Appadurai. To Kennedy (2007), 'waste' is a subjective notion: beauty is in the eye of the beholder. With 'waste', devaluation is relative and personal: one individual's trash may be another's treasure. 'Waste' has value to the right person who knows how to harness or appreciate it. Moreover, following the work of Appadurai (1988) we see waste as constituting a moment, or a stage in "the social life of things", when objects are assessed, reassessed, and recreate themselves as resources. In other words, we are more interested in various incarnations and reincarnations of materials in different situations. An important question to ask then is, under what set of conditions (or what Appadurai calls 'regimes of value') are certain materials considered perishable or durable, waste or resource? This focus on waste as "objects in motion" (to use Appadurai's apt phrase) helps us to trace the trajectories of items (plastic bottles, nets, etc.) as their lives are transformed and transform those of their users. As Appadurai (1988, p. 5) enjoined us, it is only when we follow these trajectories (or what he calls 'paths and diversions') that the lives of things help us understand how the meanings of particular objects are inscribed in their forms and their uses. Understanding waste in this

\footnotetext{
3 The authors would like to acknowledge the support of the Deutsche Gesellschaft für Internationale Zusammenarbeit (GIZ) in funding this research.
} 
way also helps illuminate the social context in which these transformations and exchanges take place.

Our analysis suggests that within Chembe village, reuse practices are both widespread and diverse, with a multitude of 'waste' items living multiple 'lives' before being ultimately discarded as trash. In the next section, we present the socio-economic context of Chembe and show how tourism has stimulated innovation in reuse practices, by providing a constantly supply of cheap, or free, desirable waste items, and opening pathways for alternative livelihoods through waste. In the next two sections, we map the patterns and sources of reuse in Chembe. In the fifth section, we focus on waste and wealth, or how the reuse of discarded items also facilitates income-generating activities. In the penultimate section, we discuss the utility of Kennedy and Appadurai's analytical lenses in our study. By way of conclusion, we examine several threads of analysis (such as the relationship between reuse and consumption, the role of social markers, the historicity of reuse practices, and interactions with indigenous knowledge), that the empirical investigation hinted at, but did not shine enough light on to allow for further inquiry. By highlighting these themes, we attempt to detail avenues for future empirical investigations, while offering cautious guidance on possible theoretical conceptualisations. This investigation is particularly important within the context of rural Africa, and the Global South more broadly. Moreover, it should inform a more nuanced, and less normatively Western waste management studies discourse, where African households are habitually treated as fraught with problems needing solutions. Rather, it is time we learnt from the African household.

\section{Chembe and Cape Maclear}

Stretching along a narrow strip of sand and clay no more than three kilometres long and less than half a kilometre deep, and sandwiched between green, thickly forested hills, and the transparent blue waters of Lake Malawi, Chembe is perhaps Malawi's most famous village. Ironically, however, few, even within Malawi know it by that name, as it is most often conflated with the name of the promontory on which it sits, Cape Maclear, site of Malawi's first permanent mission station in 1875, and now the busiest resort destination on Lake Malawi (Fig. 1). Cape Maclear and Chembe, are, nonetheless, bound up. When, visitors come, they stay at one of the many lodges that line the lakeshore, with villas and other accommodation opening on to the beach below. Swimming, boating, snorkelling, and diving are all popular activities. Nevertheless, the beach and the lake at Cape Maclear are not spaces of exclusivity. Each morning and each evening, the beach hums with activity, as hundreds of local children play, fishermen work untangling nets, locals bathe or swim in the lake, wash dishes or clothing, and the community takes advantage of both a functional and pleasant public space. Chembe itself is dense. A maze of hundreds of sandy streets winding their way through countless clay brick homes, and short, neat grass fences, marking off gardens and private yards (Fig. 2). Although most businesses that cater to tourists are near the lake, there is little distinction between tourism areas and the surrounding village, and for many international visitors, strolling through the village, and experiencing, Malawian 'village life' is one of the main attractions of visiting Cape Maclear.

However, despite the seeming timelessness of the community, Chembe has changed drastically over the past forty years. Cape Maclear and the surrounding areas were declared a national park in 1980: the first freshwater in the world. In 1984, the area became a UNESCO World Heritage site, a status which, due to poor management by the local agencies, 
it has tenuously held onto ever since (Derman and Ferguson, 1995). Once a sleepy fishing village with basic tourism offerings and only a handful of lodges, Chembe had a population of around 2000 people in the early 1990s (Smith, 1993). However, during the late 1990s and 2000s the number of lodges and tourism offerings steadily increased, drawing increasing numbers of tourists, and creating a steady and reliable source of income-earning opportunities for residents. Moreover, due to the visibility of the village as a tourism destination, local healthcare, the provision of clean water, improved roads and other social services also saw significant improvements, dramatically improving the health indicators and quality of life in Chembe (Chimangeni, 2015). Chembe lies within the Traditional Authority (TA) Nankumba, which is one of 15 TAs in the district of Mangochi. The 1987 Census did not disaggregated data at the TA level (only the district level), although the next census in 1998 did. It is therefore impossible to quantify the growth of Chembe during this period, but currently, TA Nankumba has a population of 159,775 , or about $15 \%$ of the total population of Mangochi. Importantly, $74 \%$ of the population $(117,933)$ is under the age of 30 (Malawi National Statistics Office, 2019). Young adults that may have once migrated to the city are staying and working, while people from other villages within the region are migrating to take advantage of work opportunities. As a result, the once sleepy fishing village of 2000 now has nearly 20,000 individuals. ${ }^{4}$ Its streets have become denser than ever, and some individuals have begun to build on the flood plain that separates the old village from the mountains that dominate the Lake Malawi National Park (Fig. 1).

In addition to people, tourism has also brought Chembe relative wealth, and the village is markedly more prosperous than the average Malawian village. A survey conducted in tandem with this investigation suggested that average monthly income within the village is more than double the national minimum wage: an amount that is still generally unattainable in many rural areas. ${ }^{5}$ As a result, residents generally consume at a much greater rate than other Malawians (many of whom make few daily purchases), with all the waste and consumerism that that entails. This prosperity is evident when visiting the village; local shops are busy and freshly stocked; homes are well-built and neatly decorated. Moreover, although the tourists are a steady source of jobs and other income-earning opportunities, they are also ravenous consumers and generate considerable waste: either directly, or through the lodges and restaurants they frequent. Unfortunately, Chembe's waste management services have not kept pace with its growth. Chembe has never had state-provided waste management services, and the isolation of the community (Fig. 1) limits the feasibility of transporting waste out for disposal. When the village was small, and there were few consumer goods, these arrangements were not a problem, as households produced minimal waste, and simply burned what they needed to dispose of. Growth in household consumption has dramatically increased the amount of waste produced by individual households, while the increase in population has trebled the amount of solid waste being produced. As a result, the detritus of Chembe's prosperity lies in heaps throughout the village, strewn on the side of paths, pushed into piles, or collects in low-lying areas that have become unofficial dumping grounds. Plastic bags, snack packets of all sorts, and most noticeably, broken glass, these piles dominate the back of Chembe, where the village meets the flood

\footnotetext{
4 A. Joffe, personal communication, September 2, 2019.

5 The survey suggested that the average monthly wage in Chembe is slightly more than 40,000 Malawian Kwacha (Mk) (about 50\$). The minimum wage in Malawi was revised on January 12020 from 25,000 to 35,000 Mk per month or $1400 \mathrm{Mk}$ per day (Government Gazette notice No. 68 under the Employment Act (Amendment) 2019).
} 


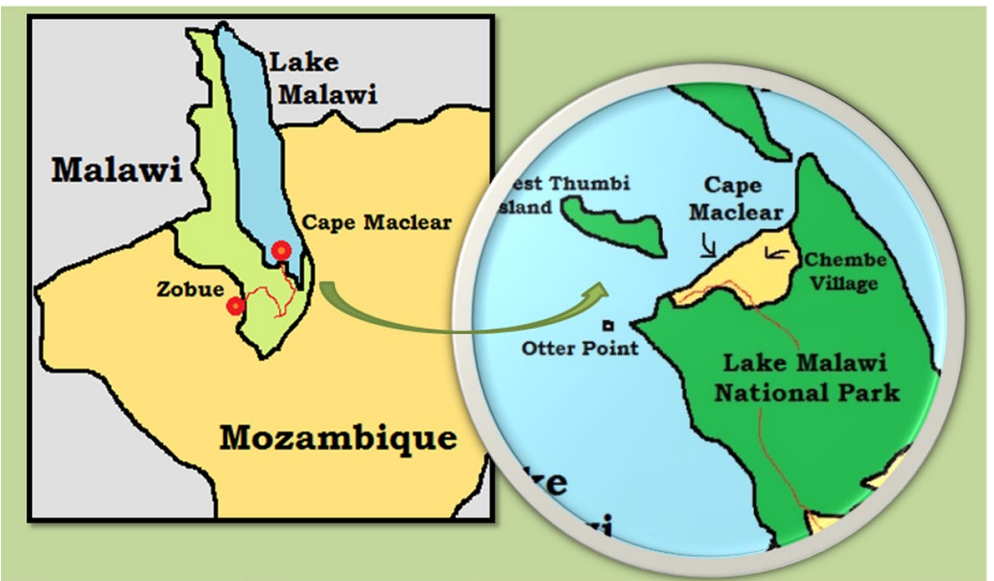

Fig. 1 Map of Cape Maclear and Chembe within Malawi (Realworld Adventures, 2019)

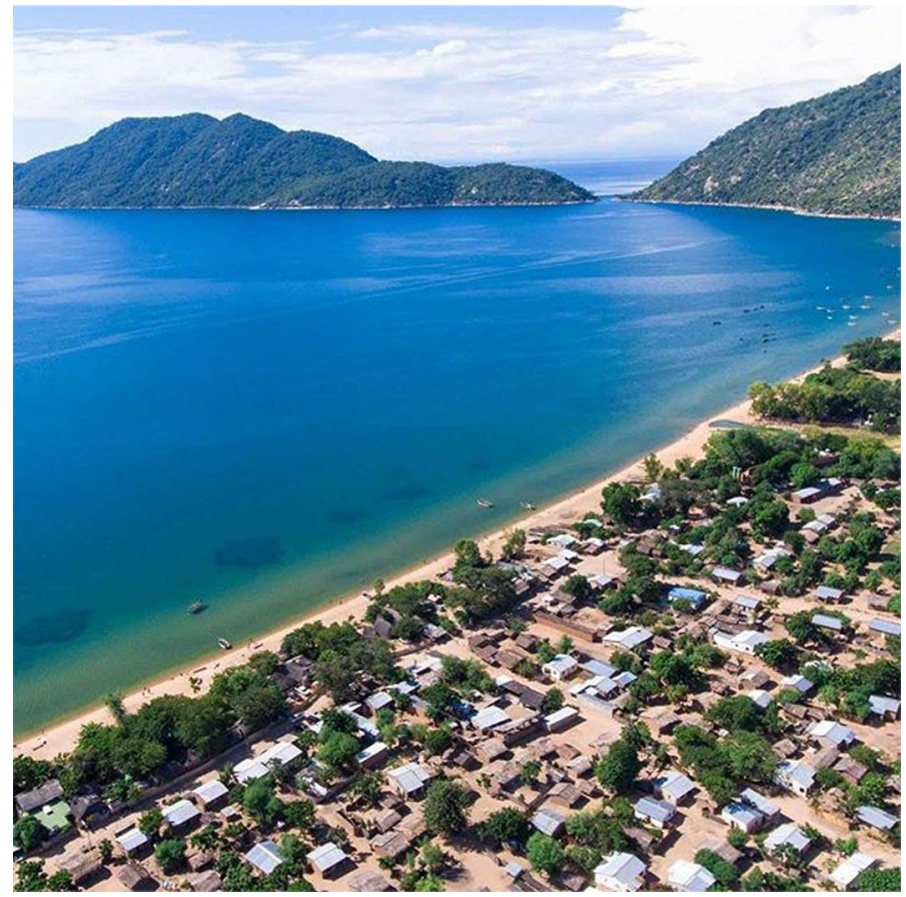

Fig. 2 Aerial photo of Chembe, showing the lake, beach, lodges, and village (Credit: P.J. Makwana, 2019)

plain, taking on the aspect of almost permanent structures, housing the unwanted remains of Chembe's consumption, as well as the occasional passing goat looking for something edible. In the past few years a number of lodge owners, responding to tourist complaints, have banded together to organise basic waste management services, including providing 


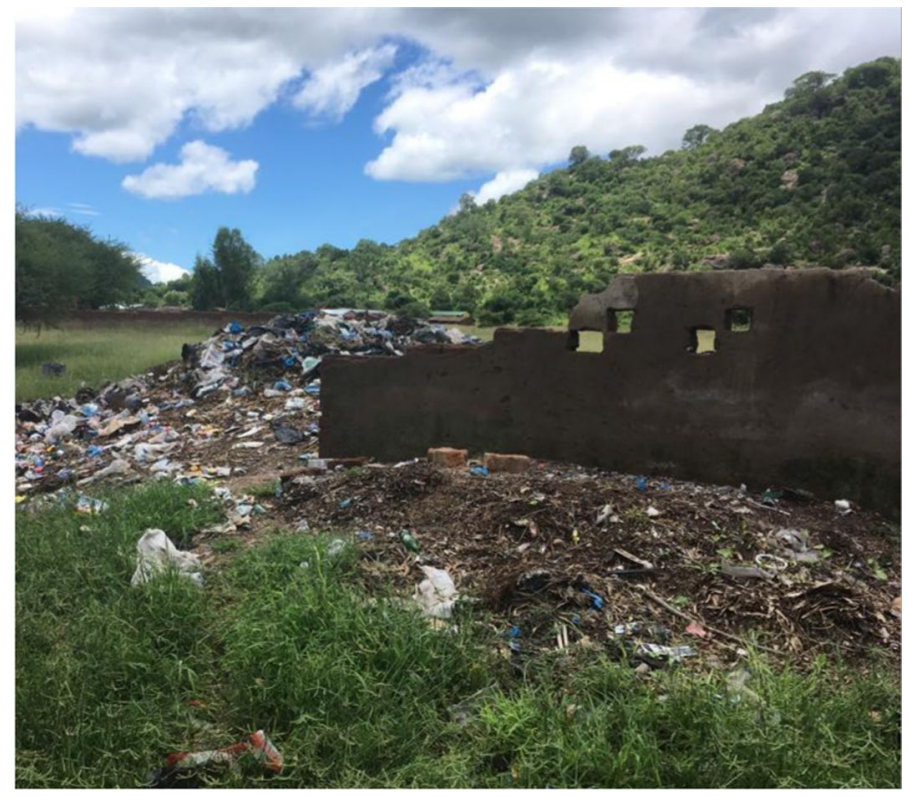

Fig. 3 Consolidated dumpsite outside of Chembe (Kalina, 2019)

and emptying waste across a number of public locations, and the consolidation of dumping to one central dumpsite (Fig. 3). These efforts however, have seen mixed results, and remain in their infancy. ${ }^{6}$

\section{Methodological approach}

This investigation was conducted as part of a broader study designed to understand and contextualise the waste status quo in the Cape Maclear area. The area was selected for its prominence, as one the nation's leading tourism destinations. The research design for the study was ethnographic, consisting of extensive and embedded qualitative fieldwork, conducted by researchers and research assistants from within the community and nearby areas. Principal data collection consisted of 46 semi-structured interviews within households, as well as semi-structured interviews with other relevant stakeholders, including tour operators, local business owners, and representatives of the many lodges that line the beachfront, pictures, observations, and field notes, conducted over a ten-day period in 2019. The interview schedule for households centred on household reuse and waste sources, while questions for other stakeholders centred on waste streams and general waste management within the community. The semi-structured nature of the interview facilitated the co-creation of knowledge between interviewer and interviewee, as respondents frequently posed questions to the researcher, and allowed for unforeseen topics to arise. Individual respondents were identified through observation and prolonged emersion within the community,

$\overline{6}$ A. Joffe, personal communication, September 2, 2019. 
aided through the taking of detailed field notes. Interviews within households were conducted in the local language (Chichewa), audio recorded, and transcribed into English. Interviews with other stakeholders, such as lodge owners or tour operators were generally conducted in English and recorded using field notes. The principal investigator conducting the interviews with community members (Bembeyere Nkhoma) is originally from an adjacent community, had lived in Chembe in the past, and was thoroughly familiar with the lifeworld of the village. Moreover, he resided in the village throughout the duration of the study and conducted the interviews with the assistance of two local students who facilitated access to households. Interviews with other stakeholders (such as lodge owners, tour guides, etc.) were conducted by the other authors, and rely on relationships and processes of action research that had been developed over several years of engagement within Chembe.

Individual schedules were developed in advance for each category of stakeholder and piloted over the first few days of data collection. This piloting allowed for the development of additional questions and the refinement of the interview schedules. Questions centred on household waste, reuse, and consumption. However, these interviews also incorporated a significant degree of participatory observation, where the researcher would spend time with respondents in their home and could observe and ask questions about specific practices as they emerged. According to Bjorholt and Farstad (2012) semi-structured interviews follow a framework of themes, but do not constrain the respondent to a particular topic. This type of interview allows for greater flexibility in questioning, and respondents are allowed greater scope for "elaboration and general discussion rather than just being presented with a set of fixed questions or questions demanding only fixed responses" (Robinson, 1998, p. 413). This format gave respondents the opportunity to address issues that they considered important and allowed for themes to emerge that may not have been identified during the pilot phase. From a constructivist perspective, meaning, developed through a conversation or interview, is seen as the product of co-production between the interviewer and the interviewee (Denzin et al., 2017). So, although responses gathered through interviews were to some degree, a response to the positionality of the interviewer, the open-ended nature of questions allowed respondents the freedom to craft their own replies, without being limited by narrow or leading questions (Rob Kitchin \& Tate, 2001).

Kalina and Scott (2019) emphasise the importance of managing gatekeeper relationships during qualitative research, particularly within rural, African contexts. Given the complex traditional governance structures within Chembe, care was made to consult with all relevant community leaders prior to the start of fieldwork. Interview respondents were chosen using a purposive or judgement sampling regimen, i.e. a subjective sampling method in which respondents are selected based on their ability to effectively contribute to the study's research objectives (Kitchin \& Tate, 2000). As noted, 46 interviews were conducted, across the ranges of stakeholders, which was the maximum feasible number that could be conducted with the time and resources available; however, the consistency of respondents' responses suggests that saturation was achieved. Participation was voluntary, and responses were recorded anonymously. ${ }^{7}$ The decision to conduct fieldwork in Chichewa, despite the existence of English as the lingua franca in Malawi was motivated by the desire to be as inclusive as possible. As Watson (2004) notes, neglecting local languages within ethnographic fieldwork may exclude more marginalised individuals, like

\footnotetext{
7 This research was approved by the National Committee On Research In The Social Sciences And Humanities in Malawi, Protocol NO. P.03/19/356.
} 
women or the poor, who are unlikely to have benefitted from the education necessary to learn the national language.

Collected data were analysed thematically. Broadly, thematic analysis is a methodology used for identifying, analysing, and reporting patterns or themes within data (Braun $\&$ Clarke, 2006). Deductively driven data analysis works 'down' from pre-existing theoretical understandings (Ezzy, 2002). Thematic analysis, on the other hand, does not begin from predefined categories, rather it allows for categories, or themes, to emerge, putting great emphasis on the interpretation and deductive abilities of the researcher. According to (Terre Blanche and Durrheim, 2006), the purpose of all forms of constructivist analysis is to reveal the cultural facets from which particular statements, texts or events have been constructed. Through the framework of a social constructivist paradigm, emphasis is placed on identifying themes that show how social constructions of reality are created and how they influence the thoughts, experiences, and decision-making of groups and individuals. From a constructivist perspective, meaning and experience are socially produced and reproduced, rather than lying inherently within individuals. Therefore, thematic analysis conducted within a constructivist framework does not focus only on an individual's motivations or understandings, but instead seeks to theorise about socio-cultural contexts and structural conditions, that enable the individual accounts collected in the field (Braun \& Clarke, 2006). As a methodology, thematic analysis is most frequently conducted using a 'coding' process which attempts to organise data under several umbrella groups or categories. A 'code,' in qualitative research, is most often a word or phrase that represents a summative or essence-capturing attribute from the data identified by the researcher-or in other words, a theme (Saldana, 2013). Data were stored, transcribed, and then coded within the software programme Nvivo, which organises materials and assists with the coding process.

\section{Findings}

\subsection{Patterns of reuse}

The most obvious path of inquiry into reuse in African households is into the specific patterns of reuse that manifest across different contexts, and within Chembe, analysis suggests that reuse practices are both widespread and diverse. Numerous waste items were identified as being reused within households, including: broken water basins which are used as trash bins, cement bags and used maize sacks which are woven into mats, chip/crisps packets and other wrappers which are crafted into household decorations, food waste which is fed to livestock, metal cans which are repurposed as flower pots, old mosquito nets which are used to cover windows and to dry fish, scrap paper which is made into decorations, or by one business, into other paper handicrafts, plastic drink bottles which are used to store various items such as cooking oil, plastic buckets which are used for storing drinking water and other items, and used clothes which are used as rags or made into mops or woven into mats. This reuse operates in layers, and an object may be reused several times before it is finally discarded. This practice corresponds to what Appadurai identifies as 'regimes of value', or how items circulate in specific cultural or socio-economic environments. In other words, the same item is transformed depending on how desire and demand, reciprocal sacrifice and power interact to create value in particular circumstances (Appadurai, 1988, p. 3 ). For instance, in our case, empty plastic buckets, which once held cooking oil are reused 
around the house to store water or for doing laundry, but when the bucket breaks or the lid will no longer seal then the bucket is repurposed as a dust bin or a flowerpot (Fig. 4). Similarly, old mosquito nets are used by villagers to cover windows, however, once they are too worn to be useful as a window screen they are spread over racks and used to dry fish (Fig. 5), as cord to bind grass fencing, or to protect flower beds from goats.

The motivations driving these reuse patterns are just as diverse as the reuse practices themselves. The overwhelmingly most cited motivation is cost: reusing a waste item around the house is cheaper than purchasing a new item to serve the same function. For these individuals, reuse is a process of conscious and informed economic decision-making. One villager described how this process of cost-benefit analysis functions within his own life:

I use old mosquito nets to cover the windows of my house as I don't have money to buy glass and planks for window covers. I also use old mosquito net as a drying rack where fish like usipa (local fish) are fully dried prior to sale. I have found that it is cheaper to use old mosquito net than gauze wire. I have been doing this for about five years. ${ }^{8}$

Similarly, the empty cooking oil buckets which are ubiquitous within the village, and are used for drawing and storing water, washing plates and other dishes, and cooking, function just the same as a store-bought, new bucket, but are much cheaper. Others reuse waste items because they are simply too poor to purchase new alternatives. For instance, one woman described using mats woven from discarded maize sacks as seating in her home because she was not able to afford chairs or store-bought mats. ${ }^{9}$ For her, repurposing a previously discarded waste item into something usable was a better alternative than not having seating for guests.

Another motivation driving reuse within Chembe is that, in many instances, these practices deliver unique or creative solutions to specific household applications or provide better alternatives than commercially available products. One widespread pattern of reuse that illustrates this dynamic is the reuse of empty plastic drink bottles to store various commodities, but specifically, cooking oil. Cooking oil arrives in the village in large five litre buckets and is sold either in bulk or in small quantities to villagers. In the past, shop owners would sell premeasured amounts of cooking oil in small plastic bags. However, many respondents described this system as unhygienic, due to the shop owners using their mouths to inflate the plastic bags prior to filling them. Although oil is still sold within the village in this way, many have switched to using washed and repurposed discarded plastic drink bottles to store oil that they purchase from shopkeepers. To respondents, this switch has had many benefits. Aside from a perceived improvement in hygiene, the lid on the bottle allows for the container to be opened and resealed, allowing for repeated reuse. Moreover, the plastic bottles are more durable than the new plastic bags, and even seen as preferable to glass bottles, because they seal well do not break easily. One villager explained the advantages of this durability, "sometimes I send my children to buy cooking oil from shops and I do not fear that they might lose some of the cooking oil because the bottles have lids". ${ }^{10}$ Although other members of the community may have once considered the bottles as waste, villagers described how they could be restored and cleaned to appear, once again, new. In addition, the old plastic bags had to be purchased, adding to the cost of the cooking

\footnotetext{
8 Interview \#1, 03/09/2019.

9 Interview \#11, 05/09/2019.

10 Interview \#16, 06/09/2019.
} 
Fig. 4 Old buckets repurposed as flowerpots in front of a home (Nkhoma, 2019)
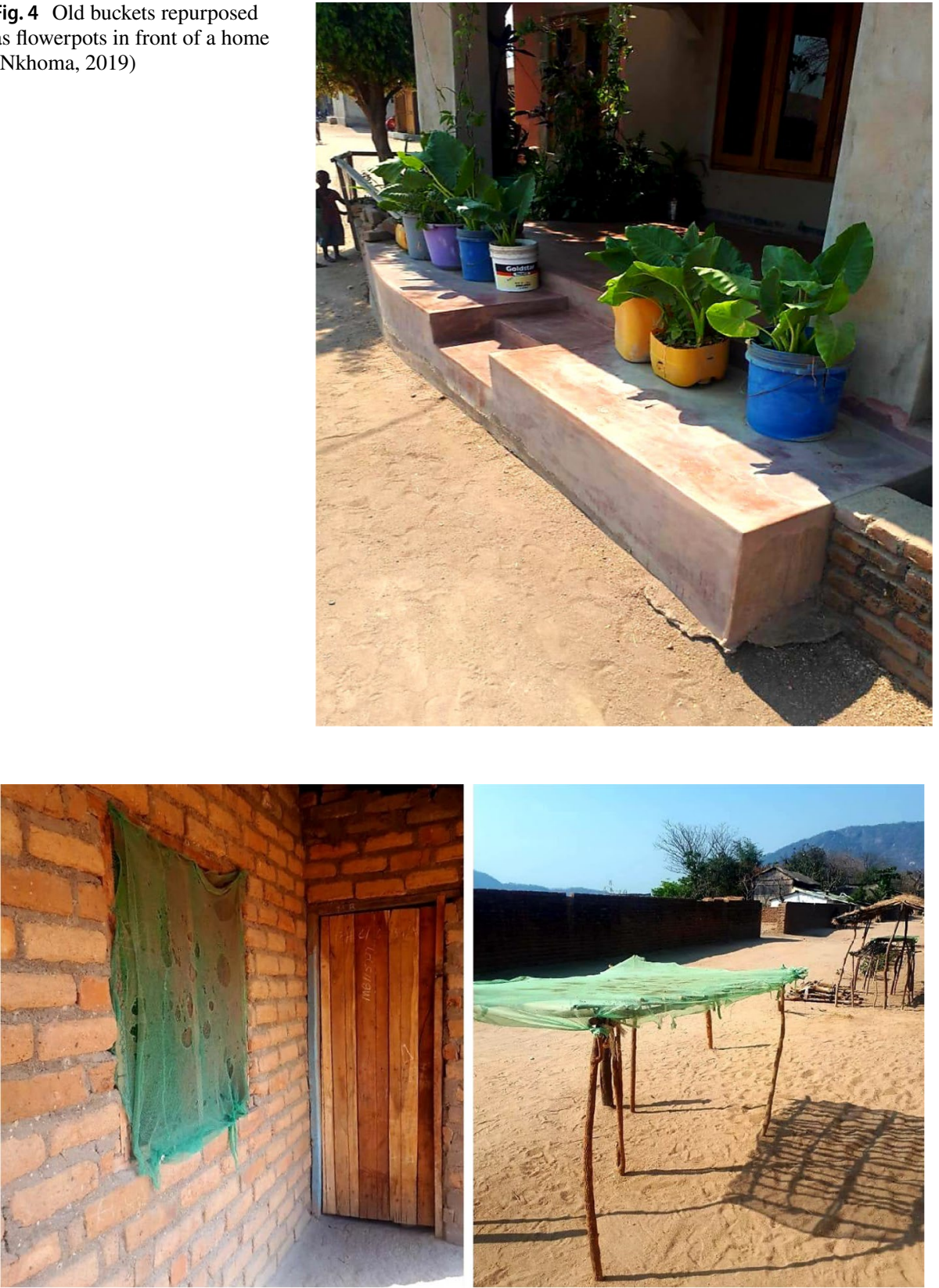

Fig. 5 Old Mosquito netting as a window covering and for drying fish (Nkhoma, 2019)

oil, while repurposed plastic bottles are both a more versatile solution, and widely available for free or little cost.

Other instances of reused waste items being better solutions than commercially available products include the cooking oil buckets themselves, which were described by several 
respondents as having stronger lids than the new buckets being sold at the market, as well as mosquito netting for various fencing and screening applications. Villagers choose to use mosquito netting for these functions because the nets have been chemically treated and are resistant to insects. One villager described using old mosquito netting as cords to bind together bundles of grass for fencing around the perimeter of his household. According to his account, there are several insects ${ }^{11}$ that eat certain binding materials, including rope and other natural fibres, as well as even rubber cords stripped from the inside of discarded tyres. ${ }^{12}$ However, strands cut from old mosquito nets have proved resistant to insects, outperforming other alternatives, and increasing the lifespan of the villagers' fencing. Finally, reuse behaviour within Chembe is not solely replacing the consumption, but is also, in a few instances, providing solutions for needs in which there are no commercially available products. For example, several residents described reusing containers such as metal cans, plastic bottles, or old plastic buckets as flower planters (Fig. 4). This has proven valuable, as newly-manufactured flowerpots are not commercially available within the village, and the common presence of goats and other domestic animals within the village makes planting in the ground a risky proposition, as one villager described:

[In the past] I was planting my flowers directly in the soil, but it was difficult because goats often ate them... Now I use plastic bottles as flower planters. These are very important to me because I can tie them to the roof and to my veranda, and that way the goats cannot eat my flowers. ${ }^{13}$

Thus, in this instance, reuse behaviours have not replaced consumption. This contrasts with circular economy narratives common in the Global North, where a popularised 'zero waste' lifestyle movement has worked to shift responsibility for waste minimisation to consumers, advocating for more sustainable living through reduced consumption of single use products (see (Cohen, 2017; Johnson, 2013; Korst, 2012; Moss, 2018)). Rather, in Chembe, reuse practices serve to address demands for goods not currently being provided for adequately or cost effectively by the market.

\subsection{Waste Sources}

These reuse behaviours are facilitated by the fact that many of the previously described waste items are widely available locally within Chembe. For most respondents, the fact that the waste items that they desired were easy to find within the village was a strong motivator driving their reuse. Three major sources of desirable waste were identified, including: the individual household, including neighbours; the broader community, specifically shops, markets, and other local institutions like the hospital, and from the tourists who visit Chembe and Cape Maclear and the lodges who host them.

The most common source of the items reused by villagers is from the waste produced by themselves and their neighbours throughout their daily routines. This can include old clothes, metal cans from empty milk powder containers, broken basins that were previously used for other household purposes, maize sacks which previously stored food and other commodities, and mosquito nets which once adorned beds. There is also significant

\footnotetext{
11 The assemblage of various actors: things, people, insects, etc., that defines the affordances of certain things within these practices would be a worthy object of further empirical and theoretical investigation.

12 Interview \#18, 06/09/2019.

13 Interview \#3, 03/09/2019.
} 
item exchange between neighbours. For instance, not every individual possesses the skill to repurpose textile waste into the locally produced mops. Similarly, weaving, for mats and other coverings, is also a niche skill. For these items, those with the skill will collect the necessary materials from their neighbours, generally for free, but often exchanging the finished products for the raw materials needed for their craft. In this regard, reuse has become an important point in shaping social relations amongst neighbours through redefining modes of exchange.

Another major source of desirable waste items is from the community spaces, businesses and institutions present within the village. For instance, still speaking to textile waste, villagers who produce mops and mats from cloth reported visiting local tailors to collect scraps and off-cuts for free when household supplies proved insufficient. ${ }^{14}$ Other items, such as old maize, cement sacks, and plastic cooking oil buckets can be purchased for a small cost from local shops, while empty paint cans and worn-out fishing nets are collected from fisherman. Piles of litter, which, in the absence of waste management services commonly form in open spaces and along roadsides throughout the village (Fig. 6), are also a source of certain types of desirable items, specifically plastic bottles and chip and other snack packets which are used by some respondents to create decorations within their home (Fig. 7). Although items from these communal piles are often dirty, and need to be washed prior to use, they have been discarded and can be collected for free. ${ }^{15}$

Next, the hospital and the Health Surveillance Assistants (HSAs) ${ }^{16}$ also indirectly provide a significant amount of reuse items for the vast majority of the community, being the principal source of free mosquito nets. As part of Malawi's ongoing campaign to eradicate malaria, the HSAs periodically distribute mosquito nets to village households at no cost (Kok et al., 2016). Moreover, replacement nets are also available for free at the village hospital for those who express a need. As previously described, these nets, once they are no longer usable for their original purpose, are widely reused, often multiple times, as window coverings, racks for drying fish, fencing, and cordage. The distribution of free nets by the HSAs and the hospital drives this reuse. Villagers reported receiving new nets even when they were not needed, and their current nets were still usable as mosquito protection. ${ }^{17}$ When they receive new nets however, they replace the ones above the bed and repurpose the still functional old nets. The constant supply of new mosquito nets drives this reuse cycle, encouraging innovative reuse practices for replaced nets. These behaviours speak to Appadurai's (1988) concept of 'paths and diversions' which reflects on questions of power: which actors drive users towards certain paths, and for those that diverge, what price do they pay? In this instance, reuse is indirectly incentivised by the state through their policy of net distribution, which encourages residents of Chembe to frequently replace their nets, even when not necessary, freeing old nets up for other uses. The degree to which this behaviour is unique to Chembe, which due to its visibility as a tourism destination, is prioritised by the Malawian Ministry of Health as well as private donors, is worthy of further investigation.

A final, but significant, source of reuse items for villagers is the rubbish discarded by the numerous tourists who visit Cape Maclear, as well as the waste generated by the ten major lodges that host them. To many respondents, both the tourists and the lodges represent an

\footnotetext{
14 Interview \#1, 03/09/2019; Interview \#10, 04/09/2019.

15 Interview \#13, 05/09/2019; Interview \#16, 06/09/2019.

16 Community health extension workers who regularly carry out home visits.

17 Interview \#2, 03/09/2019; Interview \#7, 04/09/2019.
} 


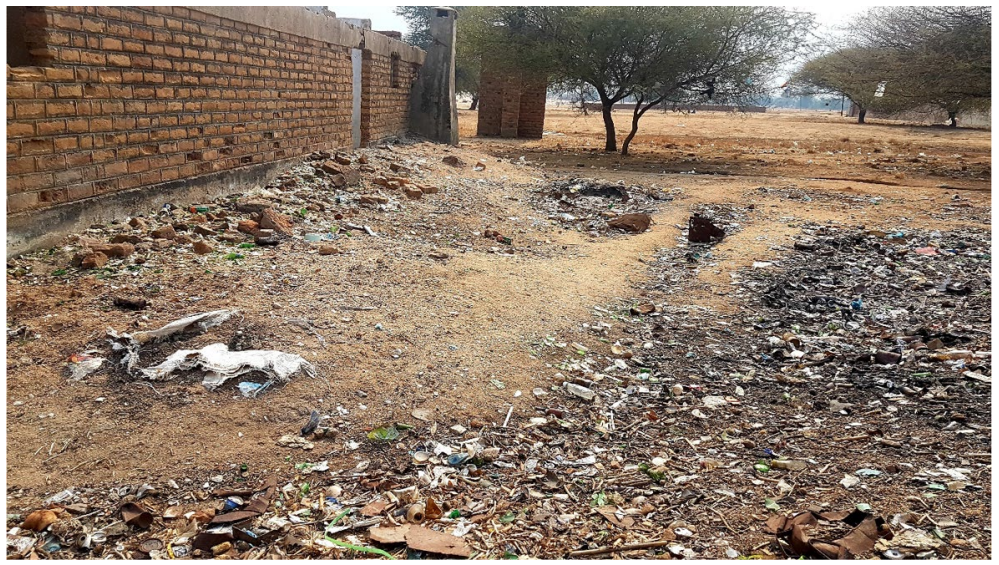

Fig. 6 Piles of rubbish alongside a path in Chembe (Kalina, 2019)

Fig. 7 Decorations made from plastic and foil chip and snack packets in a villager's home (Nkhoma, 2019)

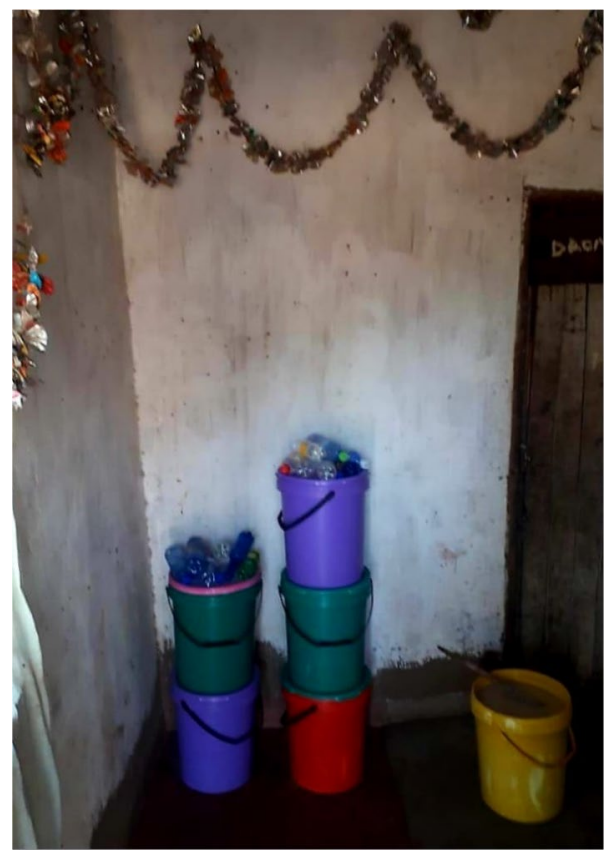

unlimited source of reuse resources, principally plastic drink bottles, for the community. Villagers reported collecting plastic bottles that tourists had discarded in public spaces like the beach and the market, collecting bottles from the main lodges, and even asking tourists for their empty bottles in person. The following quote describes this dynamic:

I get the plastic bottles from tourists at the lodges. When they have drank the water from them, I ask them to give me the used bottles. Sometimes I buy them from [lodges] for 20 
Malawian Kwacha. ${ }^{18}$ However, I only need to buy them when bottles are scarce. During holidays, there are more tourists and therefore more plastic bottles are used and dumped. ${ }^{19}$

Again, these bottles are used mostly for storing cooking oil or other commodities around the house, and the demand shows how successfully this reuse behaviour has supplemented other alternative practices, facilitated by the never-ending stream of free (or mostly free) waste items brought by tourists.

\subsection{Waste to Wealth}

These reuse practices have not only satisfied demand for products not available or otherwise unaffordable for many within Chembe, but they have also stimulated their own market for waste items, with a number of villagers reporting earning vital income from collecting and reselling desirable items or repurposing and selling crafted goods made from waste. As previously described, most reuse items are widely available for free within the village for those willing to put in the effort to collect them. However, as the quote that appeared above illustrates, for a few items, such as plastic bottles, there is such demand, that a resale market has organically arisen, allowing many to supplement their incomes by selling desirable waste items. Although plastic bottles are commonly strewn about the village, during the low season, when tourists are scarce, bottles become rare, and some villagers reported buying empty plastic bottles from lodges and other businesses within the village to meet their needs (Fig. 8). In addition to plastic bottles, metal paint cans and empty plastic buckets, which formerly held cooking oil, are cleaned and resold to villagers. Hawkers will also sell used buckets door to door, in addition to other merchandise. These items are not cheap however, with a bucket selling from between 1300 and $1500 \mathrm{Kwacha},{ }^{20}$ a significant expense for Chembe's poorest residents. ${ }^{21}$ However, they are cheaper than the new buckets sold in the market, and they function as well, if not better, making them a worthwhile investment for most.

In addition to a resale market around desirable waste items, several individuals reported transforming their reuse habits into income earning activities. It was previously mentioned that those with weaving or other crafting skills will barter with their neighbours for the raw materials, old clothes or empty maize sacks, exchanging the finished products (primarily mops, door mats, and sitting mats) in return. However, these individuals also sell their products, and for some, it represents a significant proportion of their livelihood, as one respondent described, "I also use old clothes to make door mats and many people in the village come to my house in order to order these mats for their own houses. The door mats are a good source of money for me. ${ }^{22}$ " Multiple individuals described crafting door mats out of old cloths to earn extra income, and nearly every respondent had one in their home (Fig. 9), suggesting the practice is widespread within the village. The mops, also made from scraps of old clothes, were equally widespread, but their manufacture was more specialised, with only a few individuals in the village producing them.

\footnotetext{
18 About three US Cents.

19 Interview \#13, 05/09/2019.

${ }^{20}$ Between 1.7 and 2 US Dollars; the minimum wage in Malawi is 20,000 Malawian Kwacha per month or 25 US Dollars.

21 Interview \#13, 05/09/2019; Interview \#15, 06/09/2019; Interview \#16, 05/09/2019; Interview \#18, 06/09/2019.

22 Interview \#1, 03/09/2019.
} 
Fig. 8 One villager's daily collection of plastic drink bottles (Nkhoma, 2019)

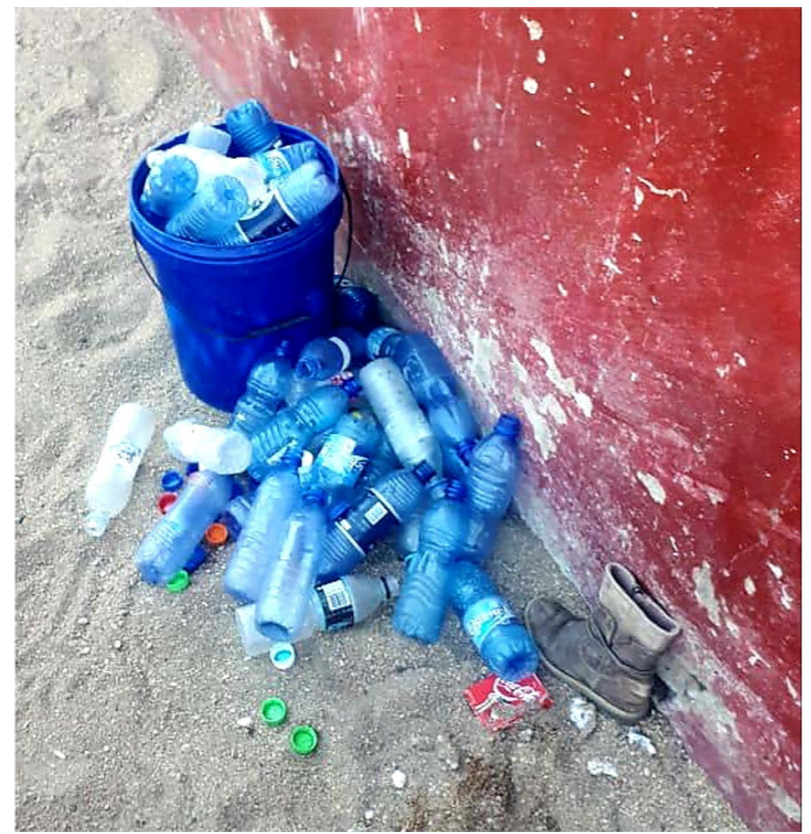

The reuse of discarded plastic drink bottles also facilitates a wide range of income generating activities. For instance, several respondents described collecting and cleaning bottles to fill with thobwa (a locally fermented beer), which they make at home and sell at the market. ${ }^{23}$ Other respondents described refilling drinking water bottles with drinking water for resale. ${ }^{24}$ Another popular use was buying cooking oil in bulk and reselling premeasured amounts to neighbours in cleaned plastic bottles. ${ }^{25}$ Finally, one villager has managed to develop an entire business around recycling, collecting waste paper, repurposing it into recycled paper, and designing and producing paper crafts to sell to tourists and the lodges. His process has transformed over the decade, incorporating various forms of waste paper. He began making post cards from labels peeled from beer bottles and selling directly to tourists. Eventually, he collaborated with a local lodge to begin hand-made paper out of waste paper from the village (Fig. 10), crafting cards and sheets of recycled paper for menus and other uses at the lodge. Three years ago, a group of lodges cooperated to purchase him a tobacco pressing machine, which allowed him to grind the waste paper into finer pieces. Less manual labour led to faster production and a higher quality final product. In order to meet his need for more input material he made a deal to collect from the hospital and other local businesses to collect their waste paper and cardboard. This instance of reuse though is an outlier and unique to Chembe, however. In most communities, paper would be scarce or quickly burned as a fire starter. Tourism has provided both the waste stream to facilitate the business, as well as the market for the individual's paper products.

${ }^{23}$ Interview \#10, 04/09/2019; Interview \#11, 05/09/2019.

${ }^{24}$ Interview \#9, 04/09/2019; Interview \#11, 05/09/2019.

${ }^{25}$ Interview \#4, 03/09/2019; Interview \#11, 05/09/2019; Interview \#13, 05/09/2019. 
Fig. 9 A doormat made from old clothes

Fig. 10 Newly created recycled paper drying in the sun (Nkhoma, 2019)
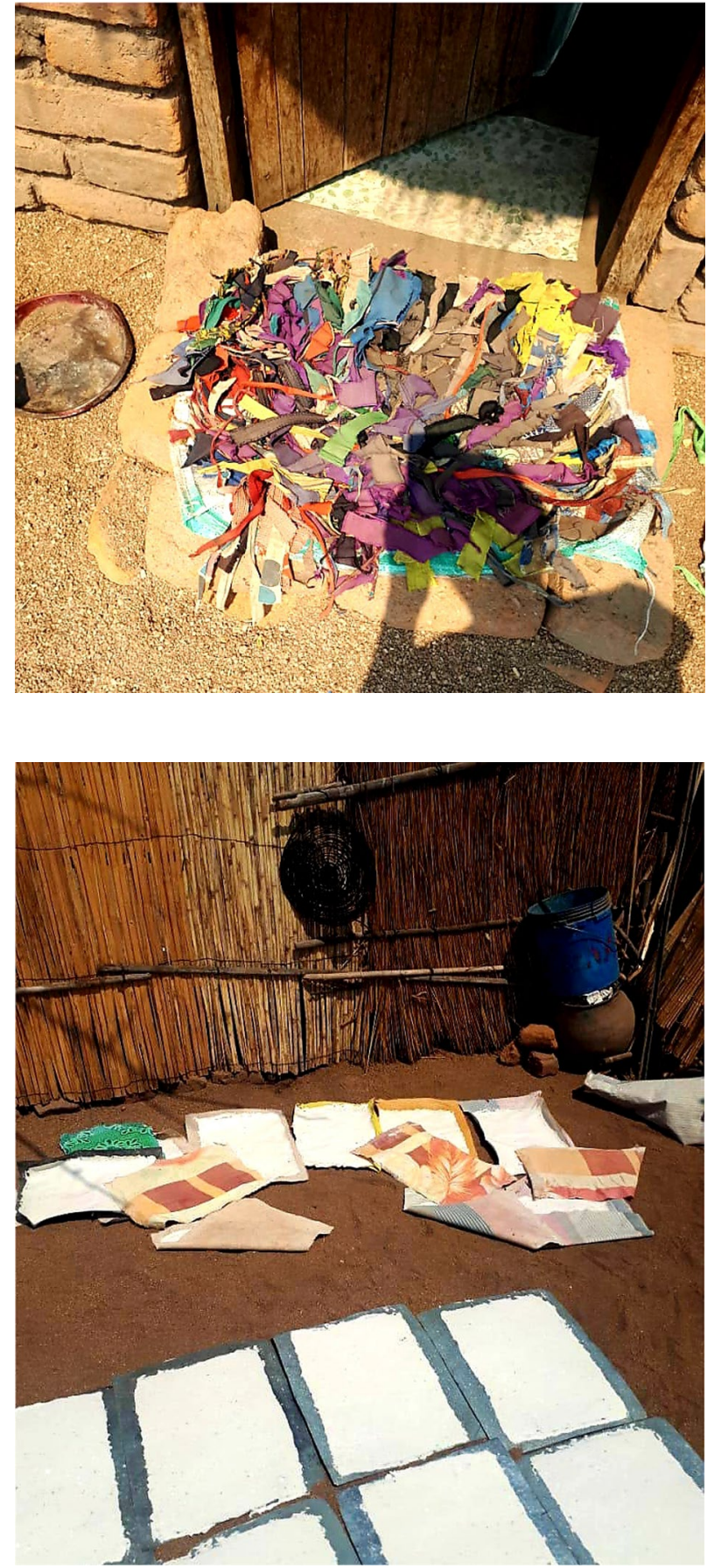


\subsection{Waste, Once Again}

In his book An Ontology of Trash, Greg Kennedy differentiates ontologically between 'waste' and 'trash'. To Kennedy (2007), the devaluation and technological objectification that engender 'waste' are both relative and subjective, however, the devaluation that engenders trash is both unconditional and absolute. Anything and everything can become waste, and if everything is waste than nothing is waste, because what one person discards, some other person likely covets (Kennedy, 2007). As Kennedy articulates, "like beauty, it appears that the phenomenon of waste belongs to the eye of the beholder, if one and the same thing can be simultaneously both waste and not waste, does waste, per se, exist at all?" (Kennedy, 2007, p. 1). The discursive elements of Kennedy's distinction between 'waste' and 'trash' unfortunately do not neatly survive the translation to Chichewa. ${ }^{26}$ However, it is clear that for the villagers of Chembe, many of the items used in the reuse behaviours described previously, and which would normatively be described as both waste and trash by most individuals throughout the Global North, are not viewed as such by respondents. They are not considered trash because they have value, they are useful to themselves to a member of their community. Either it can be repurposed into a desirable item, or it can be sold to supplement income. Therefore, these items are not viewed as waste, but as resources. In other words, recalling Appadurai (2006), our findings show that in Chembe, waste is not primarily a formerly valuable object, now degenerated. Nor is waste simply a material repository of exchange future value. It can be all these things at once, until it is none at all.

However, when does an object become 'trash' in Chembe? Kennedy (2007) would suggest that this ontological shift occurs when the object no longer has value to the beholder. When an item is no longer usable it is no longer considered 'waste' but becomes 'trash'. Respondents largely bore out this conclusion. To them, a reuse or 'waste' item became 'trash' when it was no longer usable, and was subsequently destroyed or discarded. This standard of usability varied by object and their reuse function. plastic bottles were considered 'worthless' if they lost their lids or were unable to seal properly. ${ }^{27}$ Similarly, if they become too dirty or misshapen they are generally considered to be no longer usable. Bottles that have become 'trash' are rarely discarded in Chembe though, as waste plastic is frequently used as fire starters. Chip packets and old clothes are no longer considered usable if they are too dirty or otherwise rendered unusable. Likewise, the decorations and doormats that are crafted from these items are no longer desirable if they wear out too severely and are ultimately burnt. As previously described, mosquito nets are reused several times. Mats made from maize sacks (Fig. 11) are treated the same way, when they become too damaged to serve their purpose they are replaced and destroyed.

\footnotetext{
${ }^{26}$ Chichewa, and other Southern African languages, possess numerous discursive issues of their own regarding waste which are worth further investigation,

27 Interview \#1, 03/09/2019.
} 


\section{Conclusions and recommendations}

Our research demonstrates the limited profit of seeing waste in narrow environmental terms. Using insights from Kennedy and Appadurai, we show that in Chembe, waste, like all other 'things' has its own life, with multiple economic and social affordances at various stages of production and consumption cycles. As we have shown, within Chembe reuse practices are both widespread and diverse, with a multitude of 'waste' items living multiple 'lives' before being ultimately discarded as 'trash'. The motivations driving these reuse practices are likewise diverse, though the overwhelming reason is cost: reusing a waste item around the house is cheaper than purchasing a new item to serve the same function. For these individuals, reuse is a process of conscious and informed economic decisionmaking. These reuse practices have not only satisfied demand for products not available or otherwise unaffordable for many within Chembe, but residents have also stimulated their own market for waste items, with a number of villagers reporting earning vital income from collecting and reselling desirable items, or repurposing and selling crafted goods made from waste. These behaviours are facilitated by the fact that many desirable waste items are widely available locally within Chembe, and although some of these reuse practices may be widespread within Malawi, others have been uniquely fostered by Chembe's position as an affluent tourism destination with abundant and easily accessible waste streams. The extent to which these behaviours occur in other districts, where waste materials are less commonly available, ${ }^{28}$ would be a valuable line of further enquiry. It must be emphasised that Chembe is not a normal village and has access to far more wealth and waste, than most Malawian contexts. Finally, once an object has come to the end of its usefulness, a standard that varies from object to object, it passes from 'waste' to 'trash', an ontological shift described by Kennedy and borne out by our findings, and is ultimately discarded or destroyed. As previously noted, Chembe has no state-provided waste management services, however, were interventions to occur, these findings would have significant ramifications for their potential design.

Unfortunately, none of the reuse practices that we observed made use of the significant and ever-growing quantities of glass waste that comes from the numerous lakeside bars and the tourists who frequent them. Most brand-name bottles are returned for a deposit, but not all brands carry a deposit and the nature of excessive drinking in the Malawian heat means that many of the bottles, returnable and not, get broken. With few obvious or safe reuse options, most glass is simply stockpiled in the vacant tract of land behind the lodges. The intermittent electricity means that local glass recycling is impractical, though the potential to use ground glass as an aggregate in locally made clay bricks, is worth further attention.

There is a tendency now, among eco-conscious travellers and the markets that cater to them, to highlight and flog locally made, ideally recycled, souvenirs and tchotchkes. While not detrimental per sé, future development efforts must be careful not to frame recycling and re-use as things that are done for money or to impress the white visitor, but rather focus on and strengthen the important and culturally grounded activities that have long existed, and continue to exist at household level, for all the reasons we have put forth.

To conclude, there is much that we still need to unravel in how waste and reuse is conceptualised and experienced across various African contexts. If, as we have argued, various incarnations of waste produce different values depending on the user and the context, much work

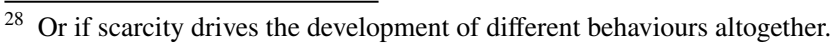




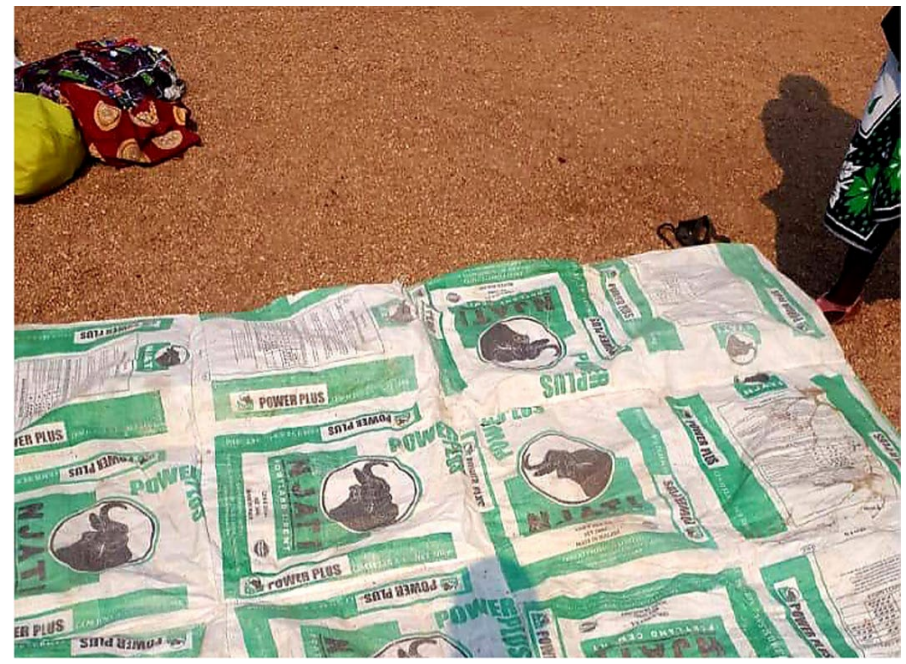

Fig. 11 A large mat made from old maize meal sacks (Nkhoma, 2019)

needs to be done to explore how waste shapes and is reshaped by various socio-cultural norms and socio-economic aspirations. During this investigation several themes emerged which we were not able pursue, which hint at avenues for future empirical research. These include: the relationship between reuse and consumption, which though hinted at in the text, could be quantified more clearly; the role of social markers in reuse, and unique social dynamics that these behaviours foster and interact with; the historicity of reuse practices and the interactions with indigenous knowledge, which of these practices predate the tourism industry and how are they rooted in traditional knowledge and practices; cross-national comparisons, much of the research on waste tends to be geographically contained, how do other societies elsewhere on the African continent conceptualise waste and reuse; grounding waste discourses in culture, the cultural milieus in which waste is understood as such and not simply on the economic decision making that defines some objects as waste and others as resources, and; the flow of ideas about waste from place to place and the flow of objects across places (e.g. tourist waste in Chembe) how does it travel across borders, are these practices observable in other regional tourism destinations. These pathways should help to illuminate several fruitful avenues for further research, while helping to contribute much needed nuance and Global South voices to a waste management studies discourse, where African households have been habitually treated as problems needing solutions.

Acknowledgements We would like to acknowledge and thank GIZ for the financial support, Mgoza lodge for hosting the research team, and Doreen Emanuel for her assistance in the data collection. A draft form of this manuscript was presented at the Fifth Symposium on Urban Mining and Circular Economy, 18-20 November 2020, Virtual Event. However, the manuscript was withheld from the symposium proceedings.

Funding Open access funding provided by Swiss Federal Institute of Technology Zurich.

Open Access This article is licensed under a Creative Commons Attribution 4.0 International License, which permits use, sharing, adaptation, distribution and reproduction in any medium or format, as long as you give appropriate credit to the original author(s) and the source, provide a link to the Creative Commons licence, and indicate if changes were made. The images or other third party material in this article are included in the article's Creative Commons licence, unless indicated otherwise in a credit line to the material. If material is not included in the article's Creative Commons licence and your intended use is not 
permitted by statutory regulation or exceeds the permitted use, you will need to obtain permission directly from the copyright holder. To view a copy of this licence, visit http://creativecommons.org/licenses/by/4.0/.

\section{References}

Ablitt, J., \& Smith, J. R. (2019). Working out Douglas's aphorism: Discarded objects, categorisation practices, and moral inquiries. The Sociological Review, 67(4), 866-885. https://doi.org/10.1177/00380 26119854271

Alene, N. B. (2018). The everyday politics of waste collection practice in Addis Ababa (2003-2009). Environment and Planning C: Politics and Space, 36(7), 1195-1213. https://doi.org/10.1177/23996 54418757221

Ali, I. H., Siddeeg, S. M., Idris, A. M., Brima, E. I., Ibrahim, K. A., Ebraheem, S. A. M., \& Arshad, M. (2019). Contamination and human health risk assessment of heavy metals in soil of a municipal solid waste dumpsite in Khamees-Mushait, Saudi Arabia. Toxin Reviews. https://doi.org/10.1080/ 15569543.2018.1564144

Almasi, A., Mohammadi, M., Azizi, A., Berizi, Z., Shamsi, K., Shahbazi, A., \& Mosavi, S. A. (2019). Assessing the knowledge, attitude and practice of the kermanshahi women towards reducing, recycling and reusing of municipal solid waste. Resources, Conservation and Recycling, 141, 329-338. https://doi.org/10.1016/j.resconrec.2018.10.017

Appadurai, A. (Ed.). (1988). The Social Life of Things. Cambridge University Press.

Bjorholt, M., \& Farstad, G. R. (2012). “Am I rambling?”: On the advantages of interviewing couples together. Qualitative Research, 14(1), 3-19.

Braun, V., \& Clarke, V. (2006). Using thematic analysis in psychology. Qualitative Research in Psychology, 3(2), 77-101.

Cohen, S. (2017). Understanding the sustainable lifestyle. European Financial Review, 2019, 7-9.

Chimangeni, C. P. (2015). The benefits of tourism from community perspective of Chembe Village, Malawi. Thesis Submitted for the degree of Master of Management to the University of the Witwatersrand, Faculty of Commerce, Law and Management, Graduate School of Public and Development Management, Johannesburg, South Africa.

Denzin, N. K., Lincoln, Y. S., MacLure, M., Otterstad, A. M., Torrance, H., Cannella, G. S., ..., McTier, T. (2017). Critical qualitative methodologies. Reconceptualizations and Emergent Construction, 10(4), 482-498. https://doi.org/10.1525/irqr.2017.10.4.482

Du Bois, W. E. B. (1903). The Souls of Black Folk. A. C. McClurg \& Co.

Ezzy, D. (2002). Qualitative Analysis: Practice and Innovation. Allen \& Unwin.

Gandy, M. (2014). Recycling and the Politics of Urban Waste. Routledge.

Gutberlet, J. (2017). Waste in the City: Challenges and Opportunities for Urban Agglomerations Urban Agglomeration. IntechOpen.

Hird, M. J. (2012). Knowing waste: Towards an inhuman epistemology. Social Epistemology, 26(3-4), 453-469. https://doi.org/10.1080/02691728.2012.727195

Hird, M. J. (2017). Waste, environmental politics and dis/engaged publics. Theory, Culture \& Society, 34(2-3), 187-209. https://doi.org/10.1177/0263276414565717

Jarman-Walsh, J. (2017). Examination of a sustainable tourism destination: A case study of Huis Ten Bosch in Nagasaki, Japan. Journal of Yasuda Women's University, 45, 189-198.

Johnson, B. (2013). Zero Waste Home: The Ultimate Guide to Simplifying Your Life by Reducing Your Waste. Scribner.

Kalina, M. (2020a). Treating the symptom: A marxist reflection on 'Zero Waste' and Sardinia 2019. Detritus, 09, 4-10. https://doi.org/10.31025/2611-4135/2020.13918

Kalina, M. (2020b). Waste management in a more unequal world: Centring inequality in our waste and climate change discourse. Local Environment, 25(6), 612-618. https://doi.org/10.1080/13549839. 2020.1801617

Kalina, M., \& Tilley, E. (2020). 'Bad' Trash: Problematising Trash in Blantyre, Malawi. Detritus, 12, 187-200. https://doi.org/10.31025/2611-4135/2020.13994

Kalina, M., Tilley, E., \& Trois, C. (2020). Saving, Ignoring, 'Trashing': Reflections on 'Seeing Waste Scenarios; From Blantyre, Malawi. Paper presented at the Fifth Symposium on Urban Mining and Circular Economy, 18-20 November 2020, Virtual Event.

Kalina, M., Tilley, E., Ali, F., Woodenberg, W., Reimers, B., \& Trois, C. (2019). Blurred Lines: Agricultural Production on the Margins of a Dumpsite in Blantyre, Malawi. Paper presented at the 17th International Waste Management and Landfill Symposium, Sardinia, Italy. 
Kalina, M., \& Scott, D. (2019). "You have to say everything is nice here": Complexities of gatekeeping in qualitative research in northern Mozambique. Qualitative Research Journal, 19(3), 307-323. https://doi.org/10.1108/QRJ-12-2018-0011

Kang, D. H. P., Chen, M., \& Ogunseitan, O. A. (2013). Potential environmental and human health impacts of rechargeable lithium batteries in electronic waste. Environmental Science \& Technology, 47(10), 5495-5503. https://doi.org/10.1021/es400614y

Kennedy, G. (2007). An Ontology of Trash: The Disposable and its Problematic Nature. State University of New York Press.

Kitchin, R., \& Tate, N. J. (2000). Conducting Research in Human Geography. Prentice Hall.

Kitchin, R., \& Tate, N. (2001). Conducting Research in Human Geography: Theory Practice and Methodology. Routledge.

Kok, M., Namakhoma, I., Nyirenda, L., Chikaphupha, K., Broerse, J., Dieleman, M., ..., Theobald, S. (2016). Health surveillance assistants as intermediates between the community and health sector in Malawi: Exploring how relationships influence performance. BMC Health Services Research. https://doi.org/10.1186/s12913-016-1402-x

Korst, A. (2012). The Zero-Waste Lifestyle: Live Well by Throwing Away Less. Ten Speed Press.

Little, M. (2017). Innovative recycling solutions to waste management challenges in Costa Rican tourism communities. Journal of Environmental and Tourism Analyses, 5(1), 33-52.

Little, P. C., \& Lucier, C. (2017). Global electronic waste, third party certification standards, and resisting the undoing of environmental justice politics. Human Organization, 76(3), 204-214. https://doi.org/10. $17730 / 0018-7259.76 .3 .204$

Moore, S. A. (2012). Garbage matters: Concepts in new geographies of waste. Progress in Human Geography, 36(6), 780-799. https://doi.org/10.1177/0309132512437077

Moss, S. (2018). Striving for a low-waste lifestyle. MRS Bulletin, 43(7), 559-560. https://doi.org/10.1557/ mrs.2018.174

Okoronkwo, N. E., Igwe, J. C., \& Onwuchekwa, E. C. (2005). Risk and health implications of polluted soils for crop production. African Journal of Biotechnology, 4(13), 1521-1524.

Oloko, P. (2018). Human waste/wasting humans: Dirt, disposable bodies and power relations in Nigerian newspaper reports. Social Dynamics, 44(1), 55-68. https://doi.org/10.1080/02533952.2018.1441111

Realworld Adventures. (2019). Kayaking Cape Maclear, Malawi. Retrieved from https://realworldadvent ures.com/kayaking-cape-maclear/

Reno, J. (2015). Waste and waste management. Annual Review of Anthropology, 44(1), 557-572. https://doi. org/10.1146/annurev-anthro-102214-014146

Robinson, G. (1998). Methods and Techniques in Human Geography. Wiley.

Smith, L. (1993). Otters and gillnet fishing in lake Malawi National Park. IUCN Otter Specialist Group, 8 , 4-6.

Saldana, J. (2013). The Coding Manual for Qualitative Researchers. Sage.

Shaw, M. (2019). Plastics In "Paradise?” A Look At Plastic Consumption And Waste Management In San Pedro, Belize. Thesis submitted for MA in Applied Anthropology. San Jose State University. San Jose, CA.

Spelman, E. (2011). Combing through the trash: Philosophy goes rummaging. The Massachusetts Review, $52,313-325$.

Suradi, G. D. (2019). The Tourism Industry, Waste Management, and Vector-borne Diseases: A Case Study of Curaçao. Thesis submitted for MA in Sustainable Development. Utrecht University. Utrecht, Netherlands.

Terre Blanche, M., \& Durrheim, K. (2006). Histories of the present; social science research in context. In M. Terre Blanche \& K. Durrheim (Eds.), Research in Practice; Applied Methods for the Social Sciences (pp. 1-17). Cape Town: UCT Press.

Van Bemmel, A., \& Parizeau, K. (2019). Is it food or is it waste? The materiality and relational agency of food waste across the value chain. Journal of Cultural Economy. https://doi.org/10.1080/17530350. 2019.1684339

Van der Graaf, A. (2017). The Issues of Solid Waste Management on Small Islands: Malapascua Island Philippines as a Case Study. Thesis submitted for Masters of Advanced Studies, Center for Marine Biodiversity and Conservation, Scripps Institution of Oceanography, UC San Diego. San Diego, CA.

Viney, W. (2014). Waste: A Philosophy of Things. Bloomsbury.

Wang, B. (2019). Sacred trash and personhood: Living in daily waste-management infrastructures in the Eastern Himalayas. Cross-Currents East Asian History and Culture Review, 8(1), 224-248.

Watson, E. (2004). What a dolt one is: Language learning and fieldwork in geography. Royal Geographic Society, 36(1), 59-68. 
Weber, G., Cabras, I., Calaf-Forn, M., Puig-Ventosa, I., \& D’Alisa, G. (2019). Promoting waste degrowth and environmental justice at a local level: The case of unit-pricing schemes in Spain. Ecological Economics, 156, 306-317. https://doi.org/10.1016/j.ecolecon.2018.09.024

Wu, K.-M., \& Zhang, J. (2019). Living with Waste Becoming "Free" As Waste Pickers in Chinese Cities. China Perspectives, 2, 69-74.

Publisher's Note Springer Nature remains neutral with regard to jurisdictional claims in published maps and institutional affiliations. 